\title{
Inhibitory effect of Trolox on the migration and invasion of human lung and cervical cancer cells
}

\author{
HO JOONG SUNG ${ }^{1}$, YOONSEO KIM ${ }^{2}$, HYEREEN KANG ${ }^{2}$, JAE WOONG SULL ${ }^{1}$, \\ YOON SUK KIM ${ }^{3}$, SUNG-WUK JANG ${ }^{2}$ and JESANG KO ${ }^{2}$ \\ ${ }^{1}$ Department of Biomedical Laboratory Science, College of Health Science, Eulji University, Gyeonggi-do 461-713; \\ ${ }^{2}$ School of Life Sciences and Biotechnology, Korea University, Seoul 136-701; ${ }^{3}$ Department of Biomedical \\ Laboratory Science, College of Health Science, Yonsei University, Wonju 220-710, Republic of Korea
}

Received August 24, 2011; Accepted October 19, 2011

DOI: $10.3892 /$ ijmm.2011.832

\begin{abstract}
The antioxidant 6-hydroxy-2,5,7,8-tetramethylchroman-2-carboxylic acid (Trolox) is implicated in migration and invasion of metastatic tumors. However, the molecular mechanism underlying the effect of Trolox on metastatic cancer cells is not known. We found that a non-cytotoxic dose of Trolox decreased phorbol 12-myristate 13-acetate (PMA)-induced invasion and migration of both A549 and HeLa cancer cells. We also found that Trolox suppressed both the expression and the proteolytic activity of matrix metalloproteinase-9 (MMP-9), and that the promoter activity of PMA-induced MMP-9 was inhibited by Trolox. Our results show that Trolox inhibits the transcriptional activity of MMP-9 by suppression of NF- $\kappa \mathrm{B}$ transactivation. These results indicate that Trolox inhibits NF- $\kappa \mathrm{B}-$ mediated MMP-9 expression, leading to the suppression of migration and invasion in lung and cervical cancer cells. Trolox is a potential agent for clinical use in preventing the invasion and metastasis of human malignant lung and cervical cancers.
\end{abstract}

\section{Introduction}

Malignant tumor cells invade neighboring normal tissues. Invasion of normal tissues permits cancer cells to enter into the blood or lymph circulation from their site of origin and to establish secondary tumors (1). Cancer invasion involves tissue remodeling that includes proteolytic degradation of the extracellular matrix (ECM) and of the basement membrane of normal surrounding tissues (2). During this process, a variety of matrix metalloproteinases (MMPs) are involved in the proteolytic degradation of the ECM. There are at least 20 known human MMPs, with new members being discovered as research progresses (3). Different MMPs act on a wide spectrum

Correspondence to: Dr Jesang Ko, School of Life Sciences and Biotechnology, Korea University, 5-1 Anam-dong, Seongbuk-gu, Seoul 136-701, Republic of Korea

E-mail: jesangko@korea.ac.kr

Key words: Trolox, cell migration, invasion, matrix metalloproteinase-9, lung cancer, cervical cancer of substrates, including collagen types I, II, III and IV, and stromyelin (4). Type IV collagen is a major structural protein of both the ECM and basement membranes. Among MMPs, MMP-2 (gelatinase-A) and MMP-9 (gelatinase-B) play crucial roles in the degradation of type IV collagen and gelatin, which are both main components of the ECM. In addition, both are highly expressed in various cancers and are closely related to invasion, metastasis, and the epithelial-mesenchymal transition in cancer cells $(5,6)$. MMP-2 is essentially expressed in metastatic cancers, while MMP-9 is regulated by diverse growth factors, cytokines and xenobiotics, such as phorbol 12-myristate 13-acetate (PMA) (7). Induction of MMP-9 is notably important in the invasive ability of human cancers, including lung and cervical cancers $(8,9)$ and suppression of MMP-9 inhibits invasion of lung and cervical cancer cells (10).

Oxidative stress is also associated with the invasive potential of cells and regulates MMPs in malignant tumors (11). Reactive oxygen species (ROS) are implicated in tumor metastasis via either an NADPH oxidase (Nox)-dependent or independent pathway (12). Nox generates ROS and mediates cytoskeleton rearrangement by induction of the transforming growth factor- $\beta$ (12). In Nox-independent ROS generation, ROS regulates gene expression of MMPs and the invasive ability of cancer cells (12). Thus, chemical or enzymological antioxidants have been studied extensively in relation to the correlation between oxidative stress and the invasive potential of cancer cells $(12,13)$. It has been demonstrated that antioxidants suppress MMP-9 expression together with an inhibition of the invasive ability of human lung and cervical cancer cells $(14,15)$.

Vitamin $\mathrm{E}$ is an important natural antioxidant and is considered to be a universal participant in antioxidant defense reactions. However, vitamin $\mathrm{E}$ is an extremely hydrophobic antioxidant in a buffered solution, and its antioxidant activity is not always consistent in experimental models (16). The antioxidant 6-hydroxy-2,5,7,8-tetramethylchroman-2-carboxylic acid (Trolox) is a water-soluble derivative of vitamin $\mathrm{E}$ that can be studied in an intact system $(17,18)$. Trolox research has been focused on its biochemical and biological applications to reduce oxidative stress or damage $(17,18)$. In addition, the correlation between the antioxidant effect of Trolox and MMP expression in inflammatory diseases and cancers has been studied $(19,20)$. Regulation of MMPs is involved in metastasis 
of human lung and cervical cancers $(4,21)$. Although various antioxidants have been studied to determine their effects on MMP expression in these cancers $(15,22)$, the effect of Trolox still needs to be determined. In this study, we demonstrate the effect of Trolox on PMA-induced invasion and migration of human lung and cervical cancer cells. Trolox regulates the $\mathrm{NF}-\kappa \mathrm{B}$ activity that induces MMP-9 expression in human lung and cervical cancer cells.

\section{Materials and methods}

Materials.PMA,Trolox,3-(4,5-dimethylthiazol-2-yl)-2,5-diphenyltetrazolium bromide (MTT) and chemicals used in a colony formation assay, including crystal violet were acquired from Sigma (St. Louis, MO). TRIzol, 5-(and-6)-chloromethyl-2',7'dichlorodihydrofluorescein diacetate (CM- $\mathrm{H}_{2}$ DCFDA) and the Lipofectamine 2000 reagent were obtained from Invitrogen (Carlsbad, CA).

Cell culture. Human lung (A549) and cervical cancer (HeLa) cells were obtained from the American Type Culture Collection (ATCC). Cells were maintained in either RPMI1640 or Dulbecco's modified Eagle's medium (DMEM) supplemented with $10 \%$ heat-inactivated fetal bovine serum, penicillin $(100 \mathrm{U} / \mathrm{ml})$, and streptomycin $(100 \mu \mathrm{g} / \mathrm{ml})$.

Cell viability and colony forming assay. Cell viabilities were measured by an MTT assay. In brief, cells were plated in a 96-well plate at a density of $1 \times 10^{4}$ cells/well. After serum starvation for $24 \mathrm{~h}$, cells were stimulated with $100 \mathrm{nM}$ PMA, and allowed to grow for $24 \mathrm{~h}$. Twenty microliters of $5 \mathrm{mg} / \mathrm{ml} \mathrm{MTT}$ solution in PBS and $100 \mu \mathrm{l}$ of DMSO was added to each well to dissolve the formazan crystals. Absorbance was measured at $540 \mathrm{~nm}$ using a plate reader (Bio-Rad Laboratories, Ltd.). For the colony forming assay, cells were plated on a 12-well plate at a density of $1 \times 10^{4}$ cells/well. After serum starvation for $24 \mathrm{~h}$, cells were stimulated with $100 \mathrm{nM}$ PMA, and allowed to grow for 10 days. Cells were then stained with crystal violet solution and colonies were imaged and quantified.

Measurement of ROS generation. Detailed methods for the measurement of ROS generation have been previously described (23). Briefly, $5 \mu \mathrm{M}$ CM- ${ }_{2}$ DCFDA (DCF) was loaded and incubated for $15 \mathrm{~min}$ in a tissue culture incubator. Prior to observing the ROS generation, cells were washed twice with pre-warmed PBS. Fluorescence images were taken by a Zeiss inverted fluorescence microscope under same exposure conditions using the AxioCam software. To quantify ROS generation, a fluorescence 96-well plate reader (Zenyth Microplate Multimode Detector, Austria) was used.

Wound healing assay. Cells were maintained up to 90-100\% confluence before scratched by a $\mathrm{P}-10$ pipette tip. Pictures were taken at 0 and $24 \mathrm{~h}$ after scratch by a Zeiss inverted microscope using the AxioCam software and the wound-healing gap distance was measured.

In vitro invasion assay. Matrigel (Sigma) was coated in polycarbonate nucleopore filters $(8-\mu \mathrm{m}$ pore size) and filter cassettes were inserted in 24-well transwell chambers.
Equal numbers of cells were loaded onto matrigel-coated filter cassettes with serum-free complement medium. PMA and Trolox were applied to the outside of filter cassettes of 24-well transwell chambers as indicated. After $24 \mathrm{~h}$ incubation, migrated cells were stained using hematoxylin and eosin. Pictures were obtained by a Zeiss inverted microscope using the AxioCam software and migrated cells were quantified.

Luciferase reporter assay. Luciferase assays were performed using the Luciferase Assay system (Promega Corporation, Madison, WI). Transfected cells were washed twice with icecold PBS and lysed in the culture dishes with reporter lysis buffer. Luciferase activities were recorded in a Luminometer 20/20n (Turner Biosystems, Sunnyvale, CA) according to the manufacturer's instructions. Luciferase activity was normalized with $\beta$-galactosidase activity. For $\beta$-galactosidase assay, pSV- $\beta$ galactosidase was co-transfected with the luciferase reporter gene. Cell extracts were assayed for $\beta$-galactosidase activity using the $\beta$-galactosidase enzyme assay system (Promega) and analyzed by a DU530 spectrophotometer (Beckman Instruments, Fullerton, CA). The ratio of luciferase to $\beta$-galactosidase activity was determined in triplicate samples. All data are presented as the mean \pm SEM of at least three independent experiments.

Reverse transcriptase-polymerase chain reaction (RT-PCR). RNA was isolated from cells using TRIzol according to the manufacturer's instruction. cDNA was reverse-transcribed from $1 \mu \mathrm{g}$ total-RNA using the Superscript First Strand cDNA Synthesis kit (Bioneer, Daejeon, Republic of Korea). Primer sequences were as follows: 5'-TCCCTGGAGACCTGAGAA CC-3' (forward) and 5'-CGGCAAGTCTTCCGAGTAGTT-3' (reverse) for MMP-9; 5'-TGAGCTCCCGGAAAAGATTG-3' (forward) and 5'-TCAGCAGCCTAGCCAGTCG-3' (reverse) for MMP-2; 5'-CCATCACCATCTTCCAGGAG-3' (forward) and 5'- CCTGCTTCACCACGTTCTTG-3' (reverse) for GAPDH. GAPDH was used as an internal control. Gel pictures were obtained by a MultiImage ${ }^{\mathrm{TM}}$ Light Cabinet (version 5.5, Alpha Innotech Corp., San Leandro, CA).

Gelatin zymography. MMP-9 and -2 activities were analyzed by gelatin zymography. Briefly, cells were incubated in serum-free DMEM and the supernatants were collected after incubation for $24 \mathrm{~h}$, clarified by centrifugation, normalized to cell number, mixed with non-reducing sample buffer, and separated by electrophoresis on a $10 \%$ SDS-PAGE containing $1 \mathrm{mg} / \mathrm{ml}$ gelatin. After electrophoresis, gels were renatured by washing in $2.5 \%$ Triton $\mathrm{X}-100$ solution twice for $30 \mathrm{~min}$ to remove all SDS. The gels were then incubated in $50 \mathrm{mmol} / 1$ Tris- $\mathrm{HCl}$ (pH 7.4), $5 \mathrm{mmol} / 1 \mathrm{CaCl}_{2}$, and $1 \mu \mathrm{M} \mathrm{ZnCl}_{2}$ at $37^{\circ} \mathrm{C}$ overnight. The gels were stained with $0.05 \%$ Coomassie brilliant blue R-250 and destained in destaining solution $(20 \%$ methanol and $10 \%$ glacial acetic acid).

Statistical analysis. Data are expressed as the mean \pm SEM. Analyses were performed using the Student's t-test.

\section{Results}

Effect of Trolox on cancer cell viability. Since the effect of Trolox on cancer cell viability has not been reported, we first 

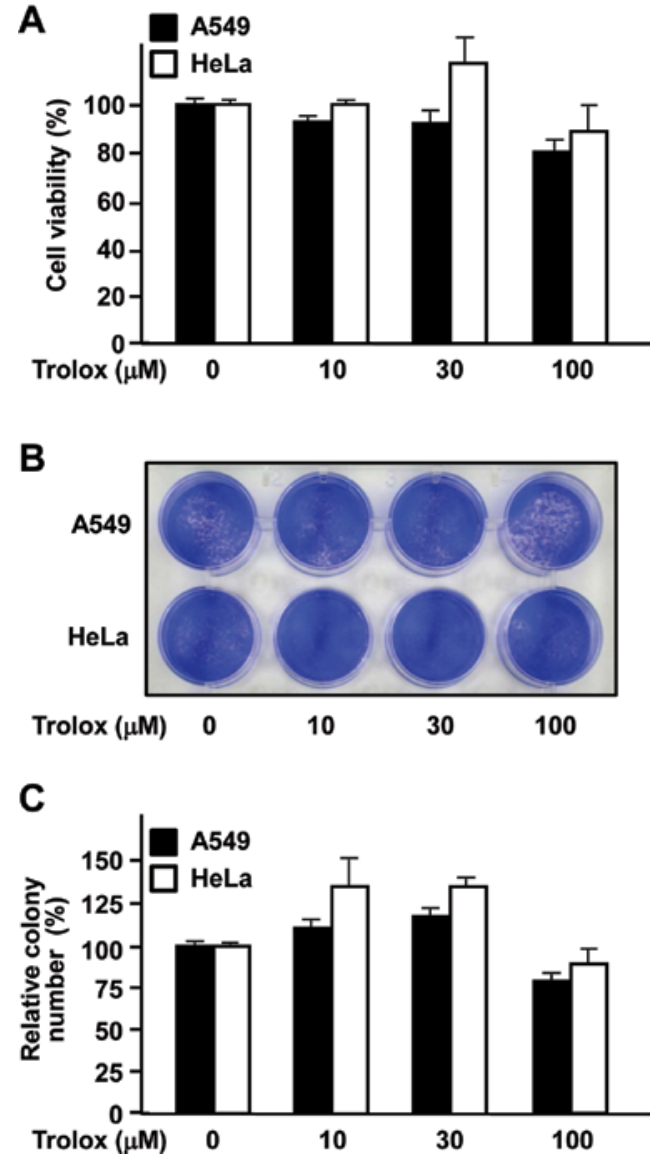

Figure 1. Effect of Trolox on cancer cell viability. (A) A549 and HeLa cells were incubated with $100 \mathrm{nM}$ PMA and the indicated concentrations of Trolox in serum containing medium for $24 \mathrm{~h}$. Cell viability was measured using an MTT assay $(\mathrm{n}=3)$. (B) Cells were plated on a 12-well plate at a density of $1 \times 10^{4}$ cells/well, and $100 \mathrm{nM}$ PMA and the indicated amounts of Trolox were treated for 10 days. Colonies were fixed with fixing solution for $10 \mathrm{~min}$ at room temperature and stained with $0.01 \%$ crystal violet solution Representative photographs demonstrating colony formation are shown. (C) The number of colonies from triplicate plates was quantified after imaging. Values are shown as the mean \pm SEM.

investigated the cytotoxic effect of Trolox on human lung and cervical cancer cells. A549 and HeLa cells were treated with $100 \mathrm{nM}$ PMA and various concentrations of Trolox for $24 \mathrm{~h}$, and the cell viability was determined using the MTT assay. A low-dose of Trolox did not affect the cell viability in either cell types (Fig. 1A). However, Trolox slightly decreased the cell viability at a concentration of $100 \mu \mathrm{M}$ by 19 and $11 \%$ in A549 and HeLa cells, respectively (Fig. 1A). To further examine the effect of Trolox on the colony formation ability of cancer cells, we performed a colony formation assay. Cells treated with Trolox at a low-dose did not exhibit any affect on their colony formation ability (Fig. 1B and C). However, treatment with $100 \mu \mathrm{M}$ Trolox decreased PMA-induced colony formation by 21 and $12 \%$ in A549 and HeLa cells, respectively (Fig. 1B and C). These results indicate that, at a low-dose (30 $\mu \mathrm{M}$ or less), Trolox has no cytotoxic effect on lung and cervical cancer cells.

Trolox inhibits PMA-induced ROS generation in lung and cervical cancer cells. Since Trolox is known as an antioxidant $(17,18)$, we examined the antioxidant effect of Trolox in the
A

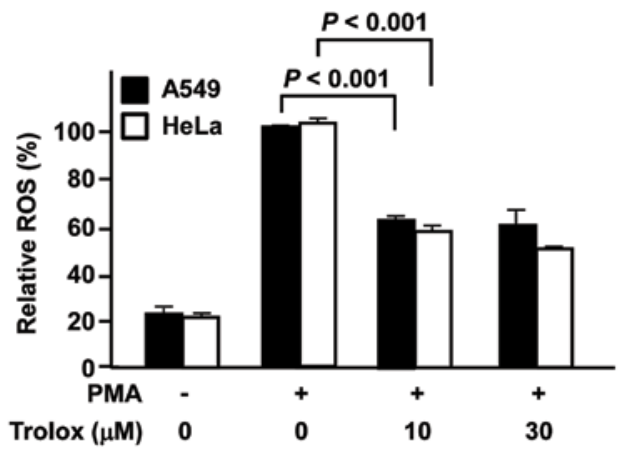

B
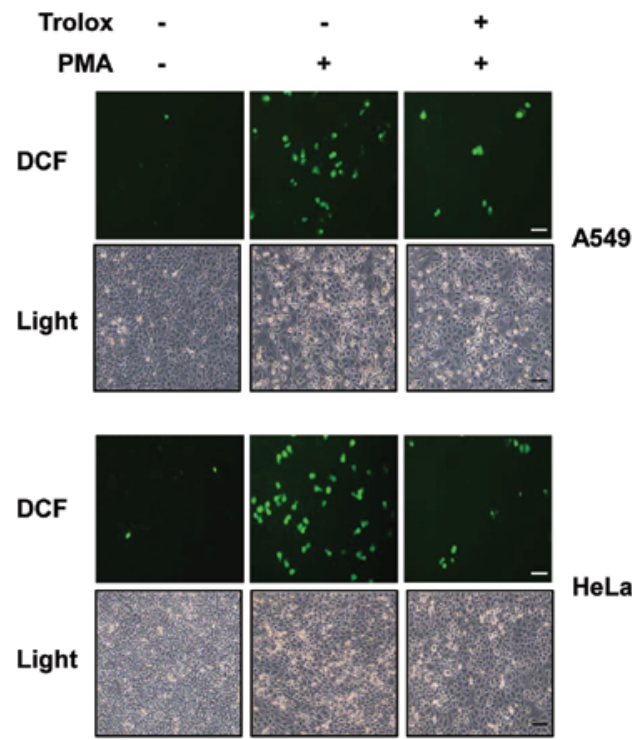

Figure 2. Trolox inhibits PMA-induced ROS generation in lung and cervical cancer cells. (A) A549 and HeLa cells were incubated with $100 \mathrm{nM}$ PMA and the indicated concentrations of Trolox in serum containing medium for $24 \mathrm{~h}$. Cells were stained with $5 \mu \mathrm{M}$ DCF for 15 min and washed with PBS twice. DCF fluorescence was measured and quantified using a 96-well fluorescence reader $(n=3)$. $P$-values were determined by Student's t-test and values are shown as the mean \pm SEM. (B) A549 and HeLa cells were incubated with $100 \mathrm{nM}$ PMA and $30 \mu \mathrm{M}$ Trolox for $24 \mathrm{~h}$. ROS generation was observed by fluorescence microscopy. Representative images demonstrating ROS generation are shown. Experiments were conducted multiple times. Scale bars, $100 \mu \mathrm{m}$.

presence of PMA, which is known to increase ROS generation (24). To determine ROS generation, DCF staining was performed. PMA increased ROS generation by $\sim 5$-fold in both cancer cell lines (Fig. 2A). A treatment of $30 \mu \mathrm{M}$ Trolox decreased ROS generation by 39 and $48 \%$ in A549 and HeLa cells, respectively (Fig. 2A). We confirmed the antioxidant effect of Trolox at a non-cytotoxic dose using fluorescence microscopic analysis. Trolox at a concentration of $30 \mu \mathrm{M}$ decreased PMA-induced ROS generation in both cancer cells (Fig. 2B). These results indicate that a non-cytotoxic dose of Trolox is an effective inhibitor of PMA-induced ROS generation in lung and cervical cancer cells.

Trolox suppresses PMA-induced cell migration and invasion in lung and cervical cancer cells. It has been reported that antioxidants suppress the migration and invasion of cancer cells $(14,15)$. There is evidence that PMA increases migration of cancer cells (25). Therefore, we examined whether Trolox 
A
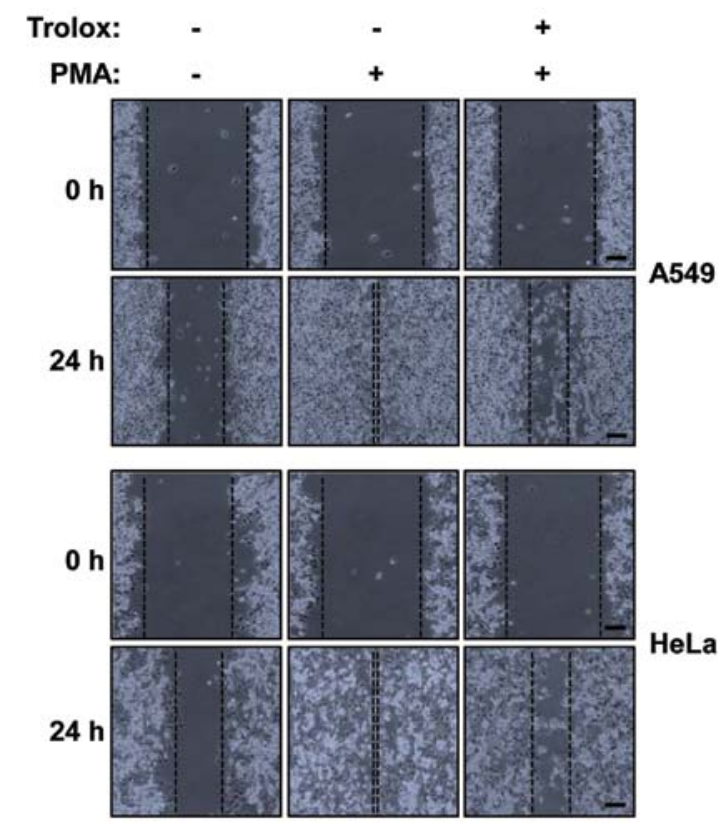

C

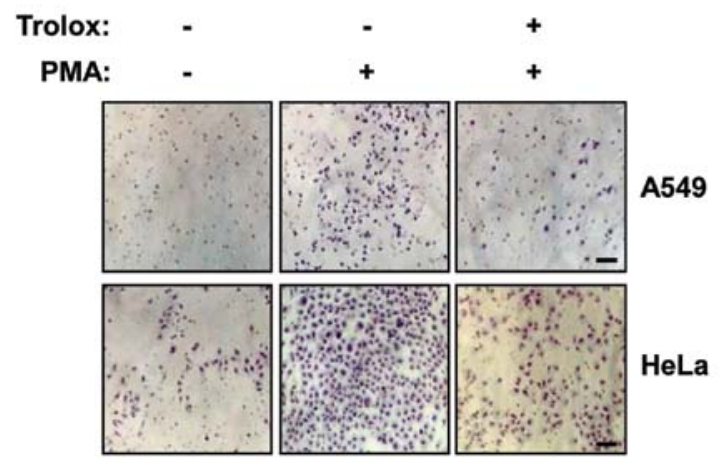

B

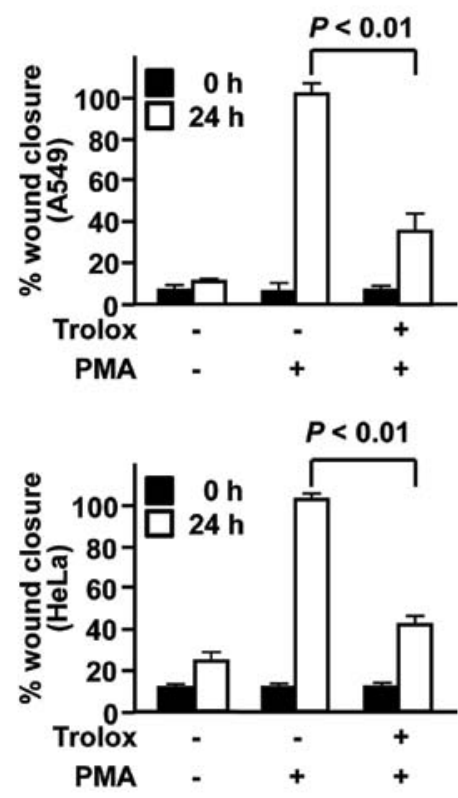

D

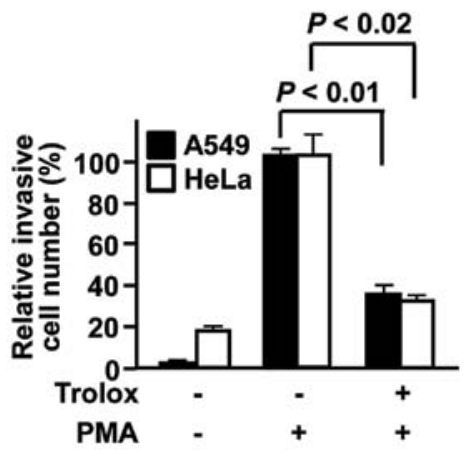

Figure 3. Trolox suppresses PMA-induced cell migration and invasion in lung and cervical cancer cells. (A) A549 and HeLa cells were scratched with a pipette tip and were incubated with $100 \mathrm{nM}$ PMA and $30 \mu \mathrm{M}$ Trolox. Representative images of wound healing were taken on the time of the scratch and $24 \mathrm{~h}$ after the wound scratch. Scale bars, $100 \mu \mathrm{m}$. (B) The level of cell migration into the wound scratch was quantified as the percentage of wound healing (n=3). P-values were determined by the Student's t-test and values are shown as the mean \pm SEM. (C) A549 and HeLa cells were incubated with $100 \mathrm{nM}$ PMA and $30 \mu \mathrm{M}$ Trolox for $24 \mathrm{~h}$. Invasion ability of cells was determined using a Matrigel invasion assay. Representative photographs demonstrating cell invasion are shown. Scale bars, $100 \mu \mathrm{m}$. (D) Cell invasion ability was quantified ( $\mathrm{n}=3$ ). P-values were determined by Student's t-test and values are shown as the mean \pm SEM.

inhibits PMA-induced migration and invasion of lung and cervical cancer cells. We performed a wound healing assay in order to examine the effect of Trolox on PMA-induced migration of A549 and HeLa cells. Cells treated with PMA caused a 9.3- and 3.9-fold increase in migration of A549 and HeLa cells, respectively (Fig. 3A and B). However, treatment with $30 \mu \mathrm{M}$ Trolox decreased PMA-induced migration by $\sim 60 \%$ in both cancer cell lines (Fig. 3A and B). We next examined whether Trolox inhibits PMA-induced invasion in lung and cervical cancer cells. A549 and HeLa cells were loaded into matrigel-coated transwells and cell invasion was examined. PMA significantly increased the invasive ability of A549 (45.4-fold) and HeLa (5.2-fold) cells (Fig. 3C and D). Trolox inhibited PMA-induced invasion at a non-cytotoxic dose by 65.1 and $68.2 \%$ in A549 and HeLa cells, respectively (Fig. 3C and D). These results indicate that Trolox effectively inhibits migration and invasion of lung and cervical cancer cells.

Trolox decreases PMA-induced expression and the proteolytic activity of MMP-9. MMP-2 is highly expressed in metastatic cancers (7). MMP-9 is also up-regulated in metastatic cancer cells and is implicated in a wide range of pathologic conditions, including inflammation and tissue repair (5). Therefore, we examined the effect of Trolox on the expression of both MMP-2 and -9 in PMA-treated cancer cells. PMA induced MMP-9 mRNA expression in both A549 and HeLa cells, whereas treatment with Trolox suppressed PMA-induced MMP-9 gene expression in a dose-dependent manner (Fig. 4A). However, the mRNA expression of MMP-2 was not affected by either PMA or Trolox treatment (Fig. 4A). We next examined the proteolytic 

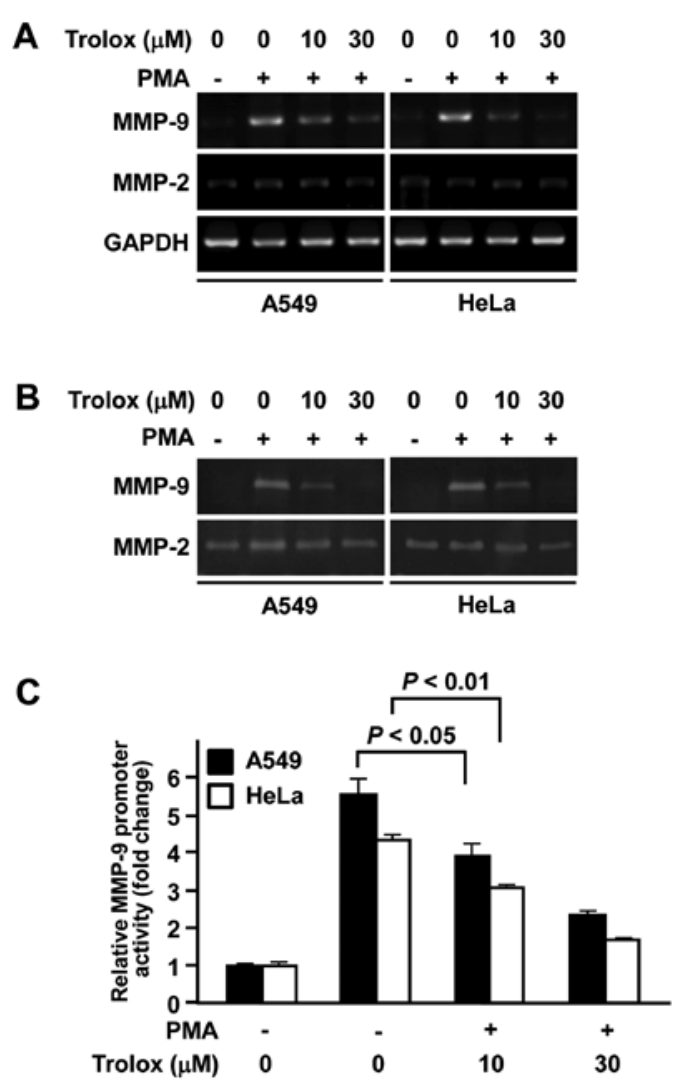

Figure 4. Trolox decreases PMA-induced expression and the proteolytic activity of MMP-9. (A) A549 and HeLa cells were incubated with the indicated concentrations of Trolox and $100 \mathrm{nM}$ PMA. After $24 \mathrm{~h}$, the mRNA level of endogenous MMP-9 and MMP-2 were measured by RT-PCR. GAPDH served as an internal control. Experiments were performed multiple times. (B) Cells were treated with $100 \mathrm{nM}$ PMA and the indicated concentrations of Trolox. After $24 \mathrm{~h}$, the conditioned medium was collected and assayed for the amount and activity of secreted MMP-9 and -2 using gelatin zymography. Experiments were conducted multiple times. (C) A549 and HeLa cells were transfected with the pMMP-9-luciferase and pSV40- $\beta$-galactosidase vectors After $24 \mathrm{~h}$, transfected cells were treated with $100 \mathrm{nM}$ PMA and the indicated concentrations of Trolox for $24 \mathrm{~h}$. Luciferase activity was normalized by $\beta$-galactosidase activity $(n=3)$. P-values were determined by Student's t-test and values are shown as the mean \pm SEM.

activities of MMP-2 and -9 using zymography. Trolox decreased the proteolytic activity of PMA-induced MMP-9 in a dosedependent manner (Fig. 4B). The proteolytic activity of MMP-2 was not affected by either PMA or Trolox treatment (Fig. 4B). Since Trolox inhibits PMA-induced MMP-9 expression at the transcriptional level, we examined the effect of Trolox on the transcriptional activity of MMP-9 using a luciferase reporter assay. PMA increased the MMP-9 promoter activity by 5.6and 4.3-fold in A549 and HeLa cells, respectively (Fig. 4C). However, treatment with Trolox decreased the promoter activity of MMP-9 in a dose-dependent manner in both cancer cells (Fig. 4C). These results indicate that Trolox inhibits the PMA-induced transcriptional activity of MMP-9 in lung and cervical cancer cells.

Trolox inhibits the PMA-induced transcriptional activation of $N F-\kappa B$. Since oxidative stress regulates NF- $\kappa \mathrm{B}$ and AP-1, which are both important modulators of MMP-9 transcription in response to PMA $(12,26)$, we examined whether Trolox
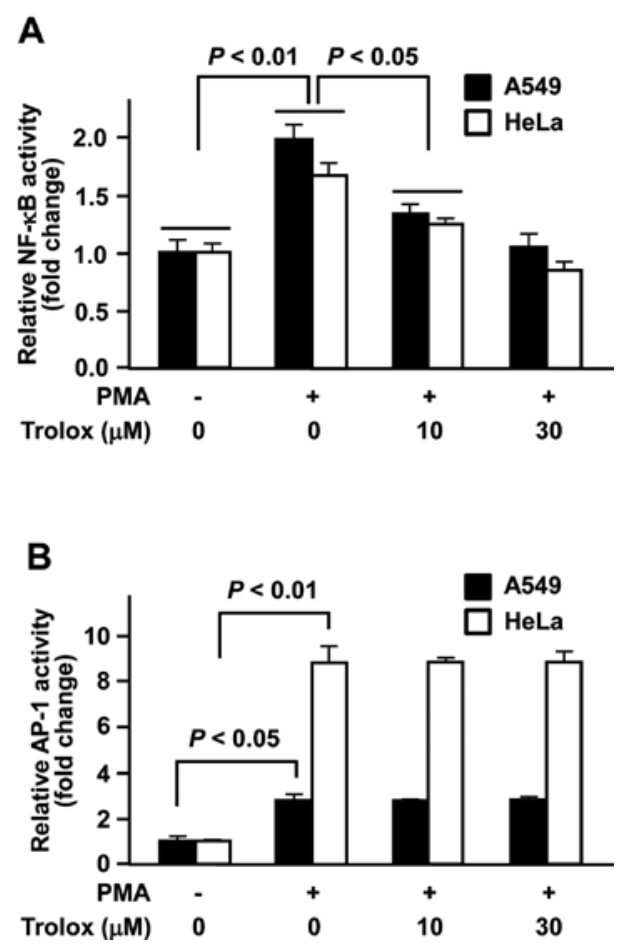

Figure 5. Trolox inhibits the PMA-induced transcriptional activation of $\mathrm{NF}-\kappa \mathrm{B}$. (A and B) A549 and HeLa cells were transfected with the reporter plasmids containing tandem NF- $\kappa$ B and AP-1 binding sites and pSV40- $\beta$ galactosidase vectors. After $24 \mathrm{~h}$, cells were treated with $100 \mathrm{nM}$ PMA and the indicated amounts of Trolox for $24 \mathrm{~h}$. Luciferase activities were normalized by $\beta$-galactosidase activity $(n=3)$. P-values were determined by Student's $\mathrm{t}$-test and values are shown as the mean \pm SEM.

affects the transcriptional activation of NF- $\mathrm{kB}$ and AP-1. Cells were co-transfected with NF- $\kappa \mathrm{B}-$ luc or AP-1-luc constructs and pSV- $\beta$-galatosidase for $24 \mathrm{~h}$, and the luciferase activity was determined. Results showed that PMA increased both $\mathrm{NF}-\mathrm{kB}$ and AP-1 transactivation, whereas treatment with Trolox decreased only the NF- $\kappa \mathrm{B}$ activity, in a dose-dependent manner in both A549 and HeLa cells (Fig. 5A and B). These results indicate that Trolox probably inhibits PMA-induced MMP-9 expression via NF- $\kappa$ B-mediated MMP-9 transcription.

\section{Discussion}

Metastasis is involved in most cancer-related deaths, due to the difficulty of controlling tumor growth and spread (27). Therefore, investigation of the role of MMPs in tumor invasion and metastasis would be valuable for developing therapies for prevention of tumor cell spread. Although the pattern of MMP expression varies within tumors, many studies have focused on determining potential inhibitors of MMPs. Among the MMP family, MMP-2 and -9 have been studied extensively for their potential use in the diagnosis and prognosis of metastatic cancers (27). Human lung and cervical cancers are known to be metastatic and previous studies have demonstrated the importance of MMP-9 in these cancers. Suppression of MMP-9 decreases the invasion and migration of human lung and cervical cancer cells (8-10). Therefore, the examination of a potential inhibitor of MMP-9 is a worthy endeavor to contribute to the treatment of these cancers. 
Many synthetic inhibitors of MMPs, including MMP-9, have been evaluated in clinical trials (28), however, inhibitors produced by natural means may be more reliable than synthetic chemicals that may induce unknown effects in the human body. Thus, we focused on vitamin $\mathrm{E}$, which is an antioxidant known to prevent metastasis and DNA damage in cancer cells (29). Instead of using vitamin E directly, we used Trolox, which is a water soluble derivative of vitamin $\mathrm{E}$, because of the hydrophobicity of vitamin E (16). In this study, we used PMA to increase expression of both MMP-2 and -9 , as described in a previous study (27). PMA is also implicated in the generation of ROS (24). ROS regulates invasion and migration of cancer cells by regulating MMP expression through activation of NF- $\mathrm{KB}$ and AP-1 $(11,12)$. In our model system, Trolox decreased PMA-induced ROS generation in both human lung and cancer cell lines. However, in PMA-untreated cancer cells, we did not observe the antioxidant effect of Trolox due to the low level of ROS generation.

We found that Trolox effectively decreases PMA-induced migration and invasion in human lung and cervical cancer cells. PMA increased expression and the enzymatic activity of MMP-9, whereas MMP-2 expression was not affected by PMA. Although we did not compare the basal expression levels and the activities of either MMP-2 or -9 in A549 and HeLa cells, our results support a previous report that MMP-2 is constitutively overexpressed in metastatic cancer cells (7). We also found that Trolox inhibits PMA-induced expression and the proteolytic activity of MMP-9 in both cancer cells. In addition, Trolox inhibits the promoter activity of MMP-9. It has been reported that an increased ROS level causes activation of NF- $\kappa$ B and AP-1 in cancer cells $(11,12)$. Notably, NF- $\mathrm{\kappa B}$ and AP-1 binding sites in the MMP-9 promoter are implicated in MMP-9 transcription in cancer cells (26). Therefore, we examined the effects of PMA and Trolox on the activity of both NF- $\mathrm{kB}$ and AP-1. Results showed that the activities of NF- $\kappa B$ and AP-1 are increased by PMA. However, Trolox suppressed the transactivation of only NF-кB. A previous report suggests that hydrophilic antioxidants have no inhibitory effect on PMA-induced AP-1 activity (30), and that Trolox inhibits NF- $\mathrm{kB}$ activity, which is a potential biomarker of oxidative stress (31).

In this study, we have demonstrated the inhibitory effect of Trolox on migration and invasion of human lung and cervical cancer cells via suppression of MMP-9 expression. We have also demonstrated that Trolox down-regulates MMP-9 expression through inhibition of NF- $\kappa B$ activity. Our results indicate that an important correlation exists between oxidative stress and cancer development, especially in the invasive ability of metastatic human lung and cervical cancer cells. Although the role of Trolox in metastatic cancer progression and its molecular mechanism are still unclear, this study has identified potential therapeutic targets in metastatic human lung and cervical cancers.

\section{Acknowledgements}

This study was supported by the Basic Science Research Program (2011-0017957), the Basic Research Laboratory Program (2011-0001573), and the Disease Network Research Program (2011-0027756) from the National Research Foundation of Korea (NRF), funded by the Ministry of Education, Science and Technology, Republic of Korea.

\section{References}

1. Mareel $\mathrm{M}$ and Leroy A: Clinical, cellular, and molecular aspects of cancer invasion. Physiol Rev 83: 337-376, 2003.

2. Johnsen M, Lund LR, Romer J, Almholt K and Dano K: Cancer invasion and tissue remodeling: common themes in proteolytic matrix degradation. Curr Opin Cell Biol 10: 667-671, 1998.

3. Curran S and Murray GI: Matrix metalloproteinases: molecular aspects of their roles in tumour invasion and metastasis. Eur $\mathbf{J}$ Cancer 36: 1621-1630, 2000.

4. Nelson AR, Fingleton B, Rothenberg ML and Matrisian LM: Matrix metalloproteinases: biologic activity and clinical implications. J Clin Oncol 18: 1135-1149, 2000.

5. Itoh Y and Nagase H: Matrix metalloproteinases in cancer. Essays Biochem 38: 21-36, 2002.

6. Orlichenko LS and Radisky DC: Matrix metalloproteinases stimulate epithelial-mesenchymal transition during tumor development. Clin Exp Metastasis 25: 593-600, 2008.

7. Park JH, Jeong YJ, Park KK, et al: Melittin suppresses PMA-induced tumor cell invasion by inhibiting NF-kappaB and AP-1-dependent MMP-9 expression. Mol Cells 29: 209-215, 2010.

8. Tang $\mathrm{CH}$, Tan TW, Fu WM and Yang RS: Involvement of matrix metalloproteinase-9 in stromal cell-derived factor-1/CXCR4 pathway of lung cancer metastasis. Carcinogenesis 29: 35-43, 2008.

9. Yu W, Liu J, Xiong X, Ai Y and Wang H: Expression of MMP9 and CD147 in invasive squamous cell carcinoma of the uterine cervix and their implication. Pathol Res Pract 205: 709-715, 2009.

10. Takahashi $\mathrm{C}$, Sheng Z, Horan TP, et al: Regulation of matrix metalloproteinase- 9 and inhibition of tumor invasion by the membrane-anchored glycoprotein RECK. Proc Natl Acad Sci USA 95: 13221-13226, 1998.

11. Reuter S, Gupta SC, Chaturvedi MM and Aggarwal BB: Oxidative stress, inflammation, and cancer: how are they linked? Free Radic Biol Med 49: 1603-1616, 2010.

12. Wu WS: The signaling mechanism of ROS in tumor progression. Cancer Metastasis Rev 25: 695-705, 2006.

13. Sotgia F, Martinez-Outschoorn UE and Lisanti MP: Mitochondrial oxidative stress drives tumor progression and metastasis: should we use antioxidants as a key component of cancer treatment and prevention? BMC Med 9: 62, 2011.

14. Yang J, Wei D and Liu J: Repressions of MMP-9 expression and NF-kappa B localization are involved in inhibition of lung carcinoma 95-D cell invasion by (-)-epigallocatechin-3-gallate. Biomed Pharmacother 59: 98-103, 2005.

15. Woo JH, Lim JH, Kim YH, et al: Resveratrol inhibits phorbol myristate acetate-induced matrix metalloproteinase-9 expression by inhibiting JNK and PKC delta signal transduction. Oncogene 23: $1845-1853,2004$.

16. Lúcio M, Nunes C, Gaspar D, Ferreira H, Lima JLFC and Reis S: Antioxidant activity of vitamin $\mathrm{E}$ and Trolox: understanding of the factors that govern lipid peroxidation studies in vitro. Food Biophysics 4: 312-320, 2009.

17. Barclay LR, Artz JD and Mowat JJ: Partitioning and antioxidant action of the water-soluble antioxidant, Trolox, between the aqueous and lipid phases of phosphatidylcholine membranes: ${ }^{14} \mathrm{C}$ tracer and product studies. Biochim Biophys Acta 1237: 77-85, 1995.

18. Forrest VJ, Kang YH, McClain DE, Robinson DH and Ramakrishnan N: Oxidative stress-induced apoptosis prevented by Trolox. Free Radic Biol Med 16: 675-684, 1994.

19. Haug C, Lenz C, Diaz F and Bachem MG: Oxidized low-density lipoproteins stimulate extracellular matrix metalloproteinase Inducer (EMMPRIN) release by coronary smooth muscle cells. Arterioscler Thromb Vasc Biol 24: 1823-1829, 2004.

20. Nelson KK, Subbaram S, Connor KM, et al: Redox-dependent matrix metalloproteinase-1 expression is regulated by JNK through Ets and AP-1 promoter motifs. J Biol Chem 281: 14100-14110, 2006.

21. Sheu BC, Lien HC, Ho HN, et al: Increased expression and activation of gelatinolytic matrix metalloproteinases is associated with the progression and recurrence of human cervical cancer. Cancer Res 63: 6537-6542, 2003.

22. Chu SC, Chiou HL, Chen PN, Yang SF and Hsieh YS: Silibinin inhibits the invasion of human lung cancer cells via decreased productions of urokinase-plasminogen activator and matrix metalloproteinase-2. Mol Carcinog 40: 143-149, 2004.

23. Sung HJ, Ma W, Wang PY, et al: Mitochondrial respiration protects against oxygen-associated DNA damage. Nat Commun 1: 5,2010 
24. Zhang Z, Oliver P, Lancaster JR Jr, et al: Reactive oxygen species mediate tumor necrosis factor alpha-converting, enzyme-dependent ectodomain shedding induced by phorbol myristate acetate. FASEB J 15: 303-305, 2001.

25. Nomura N, Nomura M, Sugiyama K and Hamada J: Phorbol 12-myristate 13-acetate (PMA)-induced migration of glioblastoma cells is mediated via $\mathrm{p} 38 \mathrm{MAPK} / \mathrm{Hsp} 27$ pathway. Biochem Pharmacol 74: 690-701, 2007.

26. Park SK, Hwang YS, Park KK, Park HJ, Seo JY and Chung WY: Kalopanaxsaponin A inhibits PMA-induced invasion by reducing matrix metalloproteinase-9 via PI3K/Akt- and PKCdelta-mediated signaling in MCF-7 human breast cancer cells. Carcinogenesis 30: 1225-1233, 2009.

27. Roomi MW, Monterrey JC, Kalinovsky T, Rath M and Niedzwiecki A: Patterns of MMP-2 and MMP-9 expression in human cancer cell lines. Oncol Rep 21: 1323-1333, 2009.
28. Coussens LM, Fingleton B and Matrisian LM: Matrix metalloproteinase inhibitors and cancer: trials and tribulations. Science 295: 2387-2392, 2002

29. Klein EA, Thompson IM, Lippman SM, et al: SELECT: the next prostate cancer prevention trial. Selenum and vitamin E cancer prevention trial. J Urol 166: 1311-1315, 2001.

30. Maggi-Capeyron MF, Ceballos P, Cristol JP, et al: Wine phenolic antioxidants inhibit AP-1 transcriptional activity. J Agric Food Chem 49: 5646-5652, 2001.

31. van den Berg R, Haenen GR, van den Berg $H$ and Bast A: Transcription factor NF-kappaB as a potential biomarker for oxidative stress. Br J Nutr 86 (Suppl 1): S121-S127, 2001. 